\title{
Virtual Tourism and Its Prospects for Assam
}

\author{
Shahnoor Rahman ${ }^{1}$, Dr. Amalesh Bhowal ${ }^{2}$ \\ ${ }^{I}$ Assistant Professor of ManagementDepartment of CommerceD.K.D.College, DergaonDist-Golaghat, \\ ${ }^{2}$ Professor and HEAD, Department of Commerce, AUDC Mahatma Gandhi School of Economics and \\ CommerceAssam University, Diphu Campus [a Central University]Diphu: Karbi Anglong (Assam)-
}

\begin{abstract}
Having been exposed to several tourism products and destinations, experienced, sophisticated and demanding travellers rely greatly on electronic media to obtain information about destinations, as well as to be able to communicate their needs and wishes to suppliers rapidly. The term Virtual reality is used to describe systems that attempt to replace much or all of the user's experience of the physical world with synthesised 3D material such as figures and sound. With Virtual reality, the user finds himself in the same dimension as and is immersed within the data. Though there is a presence of Assam on various ICT media, the customer communication of the state is limited to presence only. The benefits and utility of ICT and Internet based tools for effective customer communication of Assam ass tourism destination is yet to be realised. Besides virtual tourism or pervasive environment architecture, etc are totally absent from the customer communication strategies of the state.
\end{abstract}

\section{INTRODUCTION}

The use of internet technology, such as online travel communities, offers an opportunity for tourists to search for travel information, make connections with others, and make travel decisions more conveniently and cost-effectively. Gretzel and Fesenmaier (2003) assert that destination marketers should use immersive virtual reality technology to integrate sensory experience into their communication strategies, utilizing experiencebased internet marketing to support the tourist's information search and decision-making process. As Cho, Wang and Fesenmaier (2003) indicate, "when tourists are seeking information about a travel destination what they want to know is not only about physical characteristics of the destination but also the experience of the destination".

\section{NATURE OF STUDY}

This study is exploratory and descriptive in nature.

\section{OBJECTIVES OF THE STUDY}

- To study terms related to and relevant to Virtual tourism.

- To study pros and cons of virtual tours.

- To analyse responses of tourists visiting Assam regarding virtual tourism.

\section{METHODOLOGY}

This paper has been prepared using data obtained from both secondary sources including E-books, articles and websites, as well as partial primary data obtained from tourists during an ongoing research carried on by the $1^{\text {st }}$ author currently.A total of 400 (four hundred only) questionnaires were distributed among tourists who visited Assam, dividing the respondents into two categories - Domestic and Foreign. A total of 250(Two fifty only) questionnaires were distributed among Domestic tourists and a total of 150(one fifty only) questionnaires were distributed among Foreign tourists.Out of the 250 domestic tourists, duly filled-up questionnaires were obtained from 212(two hundred twelve). Out of the 150 foreign tourists, duly filled-up questionnaires were obtained from 85(eightyfive).Sampling has been done using non probability sampling (snowball sampling). The sample size was 400 (four hundred). Since the data obtained is mostly qualitative in nature, descriptive statistical tools like percentages, graphical techniques (bar diagrams), tables, etc. has been used to analyze/interprete data and draw generalizations.

\section{ANALYSIS AND FINDINGS}

Virtual worlds have been defined as "a computer-generated display that allows or compels the user (or users) to have a sense of being present in an environment other than the one they are actually in, and to interact with that environment" (Schroeder, 1996). Boulos, Hetherington, and Wheeler (2007) defined the virtual world 
as "a computer-based, simulated multi-media environment, usually running over the Web, and designed so that users can inhabit and interact via their own graphical self representations known as avatars". Extending the characteristics of a virtual world, Novak (2009) asserted that a virtual world is a simulated environment accessed by multiple users through an online interface consisting of six features including shared space, immersive 3D environments with graphical user interfaces, immediate interaction, interactivity with users, persistence, and social community. Generally speaking, virtual worlds are computer-mediated 3D environments with synchronous communication channels for human-controlled avatars to socially network with others. The term Virtual reality is used to describe systems that attempt to replace much or all of the user's experience of the physical world with synthesised 3D material such as figures and sound. With Virtual reality, the user finds himself in the same dimension as and is immersed within the data. Moreover, the experience is augmented with various sensory stimulations such as sight, sound and even touch, together with their respective feedback. These illusionary 3D worlds are created through a combination of visual, audio and kinetic effects where Virtual reality participants (in an ideally perfect implementation of the underlying theory) are able to see, hear and touch real life images which make them believe they are actually experiencing the real thing. In tourism policy and planning, Virtual reality could be used to generate a virtual tourism destination which tourism planners can enter to plan its development, assess the effectiveness of various planning measures envisaged, and the impacts on the environment and ecosystem of exceeding what is considered the ideal carrying capacity.Virtual reality technology offers a variety of potential benefits for tourism marketers including creating informative and entertaining virtual settings, immersive and engaging virtual experiences, multi-media communication, and social interaction with others globally. The technological innovations of the $3 \mathrm{D}$ virtual environment provide a new venue for the travel and tourism industry. It is important for tourism marketers to understand the influential factors that affect virtual tourist experiences and behavioral intentions within a 3D virtual tourism destination.Pervasive environments are based on a decentralized computing landscape and consist of a digital world (a virtual reconstruction of objects, scenarios, etc.) and the real users who have the feeling of immersion in the digital context by the ad hoc interface (Steventon and Wright, 2006). Efficient pervasive environments can be attained by using stereoscopic tools, which consist of a special screen connected to a computer which allows combination of two images of the same object from two different points of view, creating a 3D effect. In this way, tourists visualize 3D images through the use of glasses with polarized lens.

From a tourism point of view, pervasive environments provide the users the possibility to virtually discover a tourism destination, by exploiting the virtual reality tools and integrating in an efficient way, several input and output devices. This makes the user-computer interaction more comfortable and improves their usefulness and ease of use perception. Tourists may explore the environment and interact with the 3D objects and scenarios, by living a realistic experience, capable of enhancing the visit. The system recognises their position and movements by identifying the shadow or the body direction through a camera, and so on. Based on these data, the system modifies the displayed images by giving users a more realistic "feeling of presence". These multimodal interactions improve the level of interactivity, and as a consequence may affect the users' perception and satisfaction. These interactions provide an immersive experience in the virtual environment, by both supporting the visualization of 3D objects and scenarios, and allowing them to manipulate the scene, by simulating a real context. Hence, they get the opportunity to virtually explore the attractiveness of the tourism destination as if it is real. These powerful interactions are capable of affecting tourist's decision-making process, by influencing the creation of a detailed mental model of the destination.

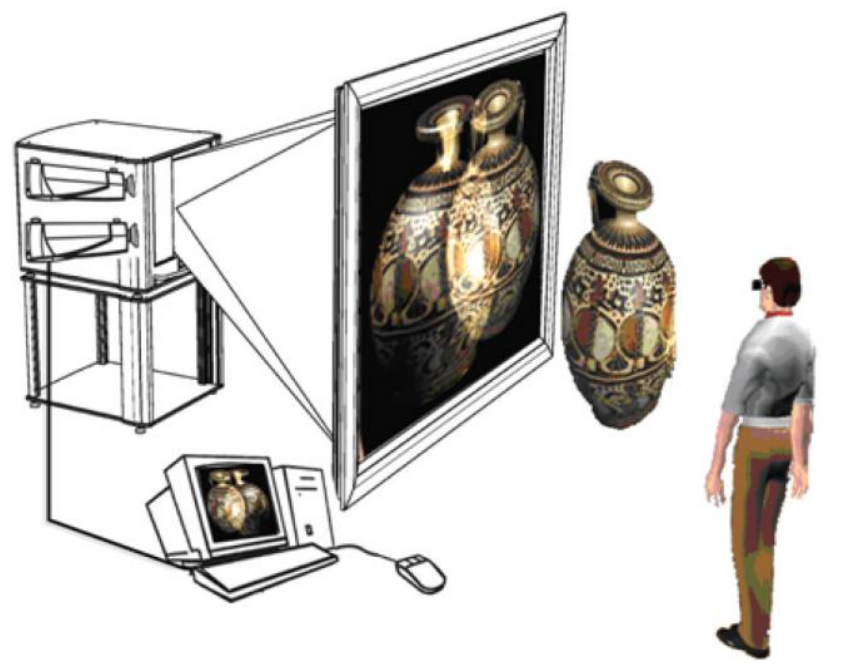

Fig- 1: Stereoscopic system for visualization of 3D environments 


\section{Pros of Virtual tourism:}

- Hassle-free holidays, where all the variables can be modified to give the tourist the perfect experience and overcome many of the problems associated with conventional holidays.

- Access to closed destinations, the past and the future, with the potential to visit inaccessible destinations like the depths of the Amazon jungle or the frozen wastes of the Antartic, or moving forward or backwards in time.

- Opportunity for disabled tourists, bringing the travel experience to those who are unable, or find it inconvenient, to travel because of physical handicaps or debilitating illnesses.

- Support for sustainability and environmental conservation, avoiding visitor resentment by the native population and the deterioration of the natural environment and the habitats of native flora and fauna.

-Virtual conferencing, which could have a serious impact in the amount of business travel.

\section{Cons of Virtual tourism:}

- The lack of the "real experience", specially given the social nature of tourism, which can facilitate the interaction with the local culture and heritage, as opposed to mere passive observation.

- The dependence of poor countries on their tourism revenues, which would affect a large number of destinations, which are both underdeveloped and remote from the larger tourism consuming areas of the world.

- Health risks, which some authors have identified as a consequence of immersion or the use of the VR equipment

- Limited reminiscence, curtailing the recording and reliving of the holiday experience and the collection of physical mementos.

- Social implications of the creation of a generation of potential VR addicts who are unable or unwilling to communicate with fellow human beings.

\section{Research findings:}

During an ongoing research on the study of Innovative Practices for effective customer communication of Assam as a tourism destination, domestic and foreign tourists were asked to state about their awareness and thoughts on the prospects of virtual tourism for communicating of Assam as a tourism destination.

As a part of the research, domestic and foreign tourists visiting Assam were asked whether they were aware about tourism destinations using virtual tour websites to communicate about the destination to tourists. Their responses are analysed as follows:

\begin{tabular}{|c|c|c|c|c|c|c|c|c|}
\hline Statement & $\begin{array}{l}\text { Type of } \\
\text { tourists }\end{array}$ & & 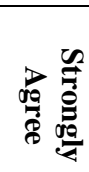 & $\underset{8}{8}$ & $\begin{array}{l}Z \\
\stackrel{3}{*} \\
0\end{array}$ & 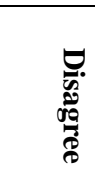 & 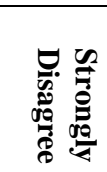 & $\overrightarrow{0}$ \\
\hline \multirow{4}{*}{$\begin{array}{l}\text { I am aware about the concept of } \\
\text { Virtual tour websites that are an } \\
\text { intelligent system, integrating } \\
\text { virtual travel experience, } \\
\text { exchange of visitors, tour } \\
\text { information and online booking } \\
\text { service, also known as 'virtual } \\
\text { tourism' }\end{array}$} & \multirow[t]{2}{*}{ Domestic } & Responses & 32 & 49 & 88 & 29 & 14 & 212 \\
\hline & & $\begin{array}{l}\text { Percentage } \\
\text { of total }\end{array}$ & 15.09 & 23.12 & 41.51 & 13.68 & 6.60 & 100 \\
\hline & \multirow[t]{2}{*}{ Foreign } & Responses & 16 & 30 & 18 & 11 & 10 & 85 \\
\hline & & $\begin{array}{l}\text { Percentage } \\
\text { of total }\end{array}$ & 18.82 & 35.30 & 21.18 & 12.94 & 11.76 & 100 \\
\hline
\end{tabular}

Table-1: Awareness of respondents about Virtual Tour Websites

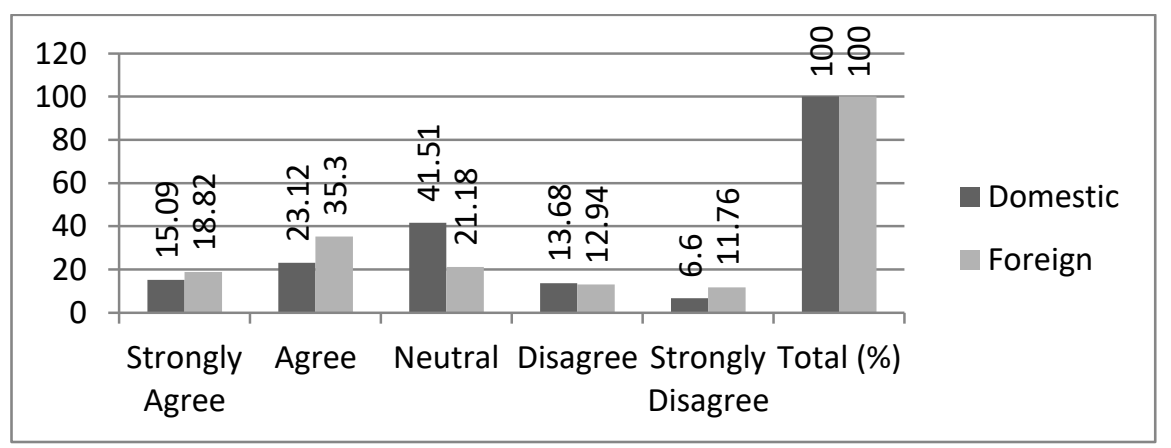

Fig-2: Percentage distribution of awareness of respondents about Virtual Tour Websites 
From the Table-1 and Figure-2 above, it is observed that $15.09 \%$ and $18.82 \%$ of domestic and foreign tourists respectively strongly agreed to being aware about the concept of Virtual Tour websites. Also, 32.12\% and $35.3 \%$ of domestic and foreign tourists respectively agreed to being aware about the concept of Virtual Tour websites. However, $41.51 \%$ and $21.18 \%$ of domestic and foreign tourists respectively were neutral to being aware about the concept of Virtual Tour websites. Moreover, $13.68 \%$ and $12.94 \%$ of domestic and foreign tourists respectively disagreed to being aware about the concept of Virtual Tour websites. Also, 6.6\% and $11.76 \%$ of domestic and foreign tourists respectively strongly disagreed to being aware about the concept of Virtual Tour websites. From the data obtained, it can be observed that there are a larger percentage of tourists from both the categories who are aware about the concept of Virtual Tour websites, compared to those who are not aware. However, the percentage of foreign tourists is more than that of the domestic ones among those who are aware about the concept of Virtual Tour websites.

During the field study, tourists were also asked to state whether they considered Virtual Tourism would be effective for communicating with tourists about Assam as a tourism destination. Their responses have been analysed as under.

\begin{tabular}{|c|c|c|c|c|c|c|c|c|}
\hline Statement & $\begin{array}{l}\text { Type of } \\
\text { tourists }\end{array}$ & & 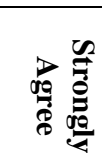 & $\underset{8}{\vec{\sigma}}$ & 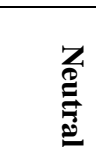 & 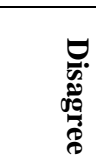 & 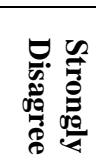 & $\overrightarrow{0}$ \\
\hline \multirow{4}{*}{$\begin{array}{l}\text { I believe virtual } \\
\text { tourism can be very } \\
\text { effectiver } \\
\text { communicating with } \\
\text { tourists of Assam as } \\
\text { a r tourism } \\
\text { destination }\end{array}$} & \multirow[t]{2}{*}{ Domestic } & Responses & 32 & 121 & 34 & 14 & 11 & 212 \\
\hline & & $\begin{array}{l}\text { Percentage of } \\
\text { total }\end{array}$ & 15.09 & 57.08 & 16.04 & 6.60 & 5.19 & 100 \\
\hline & \multirow[t]{2}{*}{ Foreign } & Responses & 17 & 36 & 22 & 6 & 4 & 85 \\
\hline & & $\begin{array}{l}\text { Percentage of } \\
\text { total }\end{array}$ & 20 & 42.35 & 25.88 & 7.06 & 4.71 & 100 \\
\hline
\end{tabular}

Table-2: Reaction of respondents regarding prospect of Virtual Tourism

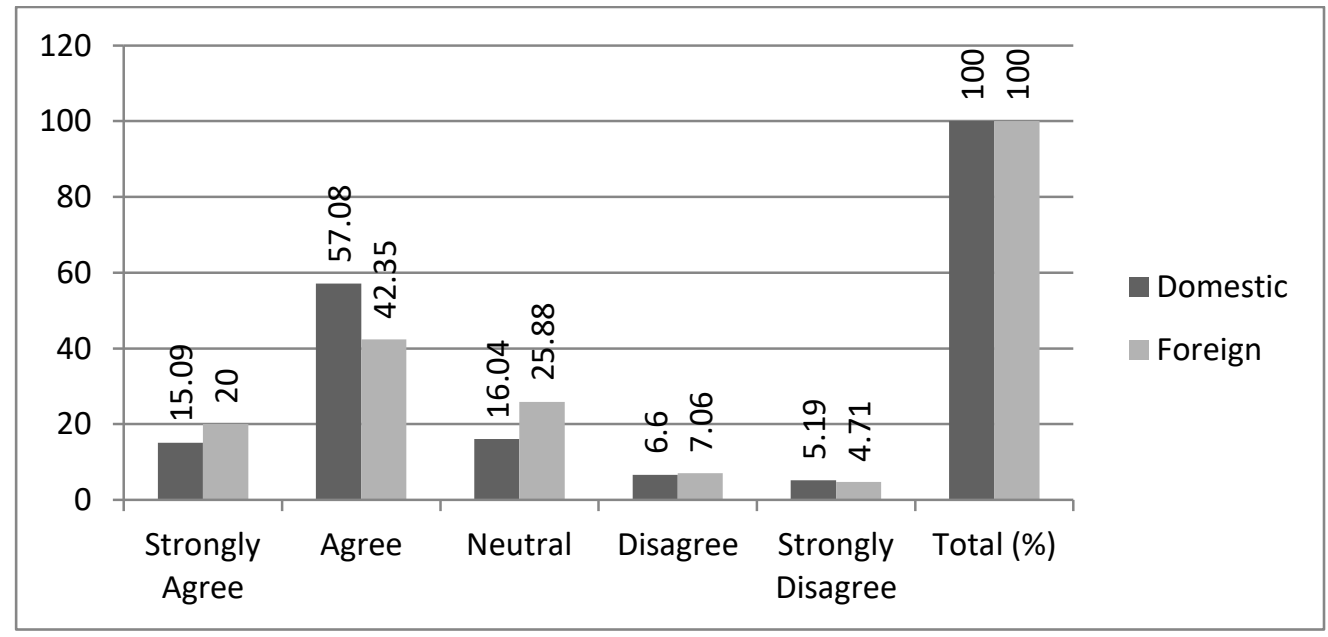

Fig-3: Percentage distribution of Reaction of respondents regarding prospect of Virtual Tourism

From the Table-2 and Figure-3 above, it is observed that $15.09 \%$ and $20 \%$ of domestic and foreign tourists respectively strongly agreed to believe that Virtual Tourism can be very effective for communicating with tourists of Assam as a tourism destination. Also, 57.08\% and $42.35 \%$ of domestic and foreign tourists respectively agreed to believe that Virtual Tourism can be very effective for communicating with tourists of Assam as a tourism destination. Besides, $16.04 \%$ and $25.88 \%$ of domestic and foreign tourists respectively were neutral to believe that Virtual Tourism can be very effective for communicating with tourists of Assam as a tourism destination. Moreover, $6.6 \%$ and $7.06 \%$ of domestic and foreign tourists respectively disagreed to believe that Virtual Tourism can be very effective for communicating with tourists of Assam as a tourism destination. Also, $5.19 \%$ and $4.71 \%$ of domestic and foreign tourists respectively strongly disagreed to believe that Virtual Tourism can be very effective for communicating with tourists of Assam as a tourism destination. From the data obtained it can be observed that a larger percentage of tourists from both the categories 
considered that Virtual Tourism can be very effective for communicating with tourists of Assam as a tourism destination. However, larger percentage of domestic tourists believed that Virtual Tourism can be very effective for communicating with tourists of Assam as a tourism destination, compared to the foreign tourists. During the research, tourists were also asked to state about their awareness about Pervasive Environments Architecture. Their responses are analysed as under:

\begin{tabular}{|c|c|c|c|c|c|c|c|c|}
\hline Statement & $\begin{array}{l}\text { Type of } \\
\text { tourists }\end{array}$ & & 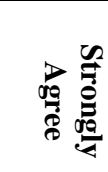 & $\begin{array}{c}\overrightarrow{0} \\
\frac{\sigma 0}{80}\end{array}$ & 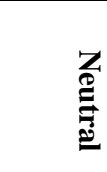 & 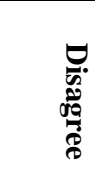 & 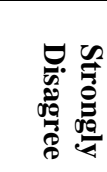 & $\overrightarrow{0}$ \\
\hline \multirow{4}{*}{$\begin{array}{l}\text { I am aware about the } \\
\text { concept of 'Pervasive } \\
\text { Environments } \\
\text { Architecture' which } \\
\text { consist of a special } \\
\text { screen connected to a } \\
\text { computer which } \\
\text { allows the } \\
\text { combination of two } \\
\text { images of the same } \\
\text { object from two } \\
\text { different points of } \\
\text { view, which creates } \\
\text { the 3D effect, where } \\
\text { tourists visualize 3D } \\
\text { images through the } \\
\text { use of glasses with } \\
\text { polarized lens. }\end{array}$} & \multirow[t]{2}{*}{ Domestic } & Responses & 19 & 25 & 91 & 49 & 28 & 212 \\
\hline & & $\begin{array}{l}\text { Percentage of } \\
\text { total }\end{array}$ & 8.96 & 11.79 & 42.93 & 23.11 & 13.21 & 100 \\
\hline & \multirow[t]{2}{*}{ Foreign } & Responses & 13 & 16 & 26 & 18 & 12 & 85 \\
\hline & & $\begin{array}{l}\text { Percentage of } \\
\text { total }\end{array}$ & 15.24 & 18.82 & 30.58 & 21.18 & 14.18 & 100 \\
\hline
\end{tabular}

Table-3: Awareness of respondents about Pervasive Environments Architecture

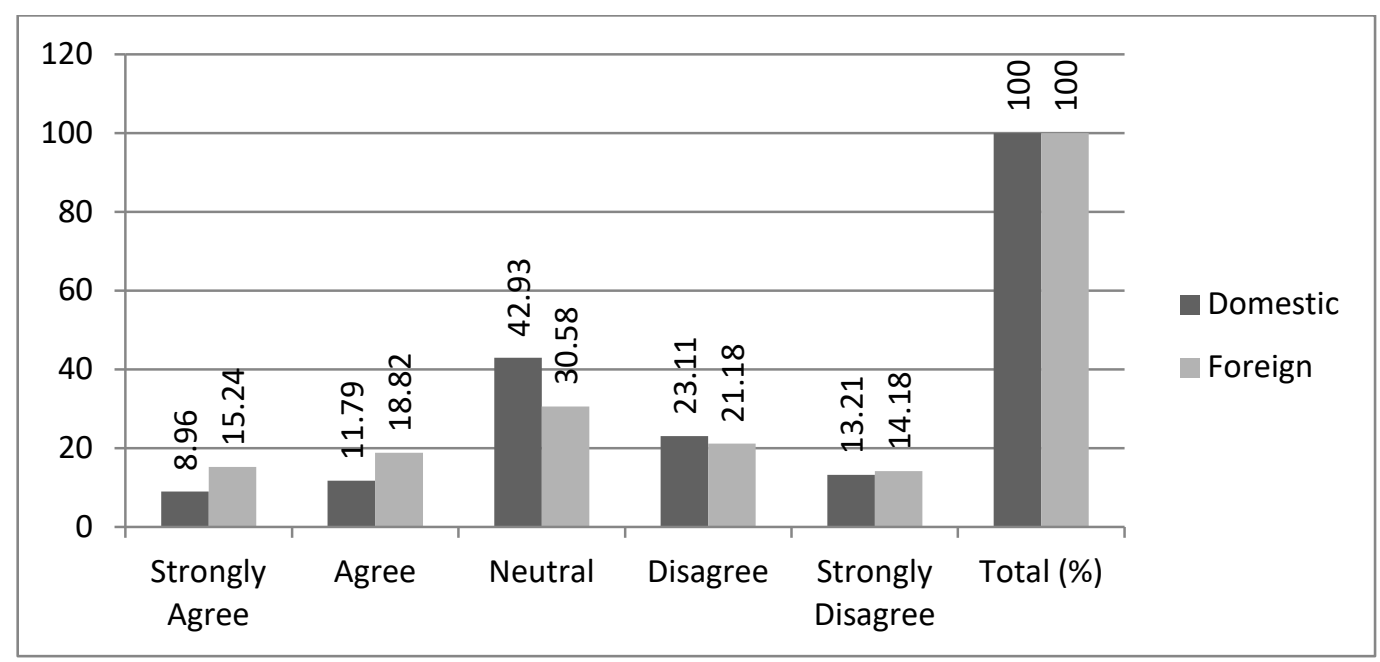

\section{Fig-4: Percentage distribution of awareness of respondents about Pervasive Environments Architecture}

From the Table-3 and Figure-4 above, it is observed that $8.96 \%$ and $15.24 \%$ of domestic and foreign tourists respectively strongly agreed to being aware about the concept of Pervasive Environments Architecture. Also, $11.79 \%$ and $18.82 \%$ of domestic and foreign tourists respectively agreed to being aware about the concept of Pervasive Environments Architecture. However, $42.93 \%$ and $30.58 \%$ of domestic and foreign tourists respectively were neutral to being aware about the concept of Pervasive Environments Architecture. Moreover, $23.11 \%$ and $21.18 \%$ of domestic and foreign tourists respectively disagreed to being aware about the concept of Pervasive Environments Architecture. Also, $13.21 \%$ and $14.18 \%$ of domestic and foreign tourists respectively strongly disagreed to being aware about the concept of Pervasive Environments Architecture. From the data obtained, it can be observed that there are a larger percentage of tourists from both the categories who are not aware about the concept of Pervasive Environments Architecture, compared to those who are aware. However, 
the percentage of foreign tourists is more than that of the domestic ones among those who are aware about the concept of Pervasive Environments Architecture.During the field study, tourists were asked to state whether they considered Pervasive Environments Architecture would be effective for communicating with tourists about Assam as a tourism destination. Their responses have been analysed as under.

\begin{tabular}{|c|c|c|c|c|c|c|c|c|}
\hline Statement & $\begin{array}{l}\text { Type of } \\
\text { tourists }\end{array}$ & & 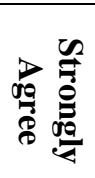 & $\underset{8}{\frac{8}{8}}$ & $\begin{array}{l}Z \\
\vdots \\
0 \\
0 \\
0\end{array}$ & 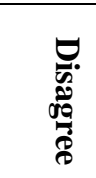 & 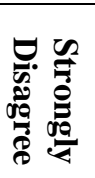 & $\stackrel{\overrightarrow{0}}{0}$ \\
\hline \multirow{4}{*}{$\begin{array}{l}\text { I believe } \\
\text { Pervasive } \\
\text { Environments } \\
\text { Architecture can } \\
\text { be very effective } \\
\text { for } \\
\text { communicating } \\
\text { with tourists of } \\
\text { Assam as a } \\
\text { tourism } \\
\text { destination }\end{array}$} & \multirow[t]{2}{*}{ Domestic } & Responses & 25 & 96 & 64 & 17 & 10 & 212 \\
\hline & & $\begin{array}{l}\text { Percentage of } \\
\text { total }\end{array}$ & 11.79 & 45.28 & 30.19 & 8.02 & 4.72 & 100 \\
\hline & \multirow[t]{2}{*}{ Foreign } & Responses & 17 & 28 & 18 & 11 & 11 & 85 \\
\hline & & $\begin{array}{l}\text { Percentage of } \\
\text { total }\end{array}$ & 20 & 32.94 & 21.18 & 12.94 & 12.94 & 100 \\
\hline
\end{tabular}

Table-4: Reaction of respondents regarding prospect of Pervasive Environments Architecture

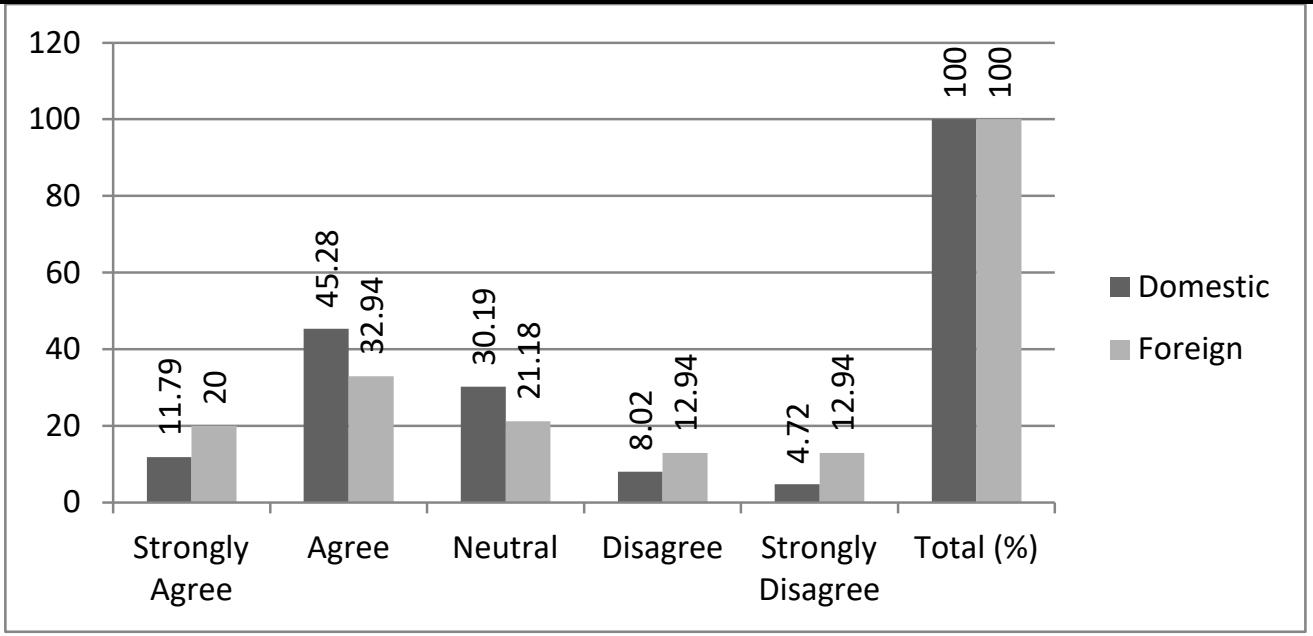

\section{Fig-5: Percentage distribution of Reaction of respondents regarding prospect of Pervasive Environments $\underline{\text { Architecture }}$}

From the Table-4 and Figure-5 above, with reference to responses of tourists to Statement-47 of the questionnaire, it is observed that $11.79 \%$ and $20 \%$ of domestic and foreign tourists respectively strongly agreed to believe that Pervasive Environments Architecture can be very effective for communicating with tourists of Assam as a tourism destination. Also, $45.28 \%$ and $32.94 \%$ of domestic and foreign tourists respectively agreed to believe that Pervasive Environments Architecture can be very effective for communicating with tourists of Assam as a tourism destination. However, $30.19 \%$ and $21.18 \%$ of domestic and foreign tourists respectively were neutral to believe that Pervasive Environments Architecture can be very effective for communicating with tourists of Assam as a tourism destination. Moreover, 8.02\% and $12.94 \%$ of domestic and foreign tourists respectively disagreed to believe that Pervasive Environments Architecture can be very effective for communicating with tourists of Assam as a tourism destination. Also, $4.72 \%$ and $12.94 \%$ of domestic and foreign tourists respectively strongly disagreed to believe that Pervasive Environments Architecture can be very effective for communicating with tourists of Assam as a tourism destination. From the data obtained it can be observed that a larger percentage of tourists from both the categories considered that Pervasive Environments Architecture can be very effective for communicating with tourists of Assam as a tourism destination. However, larger percentage of domestic tourists believed that Pervasive Environments Architecture can be very effective for communicating with tourists of Assam as a tourism destination, compared to the foreign tourists. 


\section{VI.}

\section{CONCLUSION}

Internet has revolutionised flexibility in both consumers' choice and service delivery processes and systems. Customers have now become much more sophisticated and discerning. This is because they have experienced high levels of service and also because the standard of living has grown significantly. As a result, tourists have now become more demanding, requesting high-quality products and value for their money, and more importantly, value for time. This reflects people's sheer shortage of time. Having been exposed to several tourism products and destinations, experienced, sophisticated and demanding travellers rely greatly on electronic media to obtain information about destinations, as well as to be able to communicate their needs and wishes to suppliers rapidly. Though there is a presence of Assam on various ICT media, the customer communication of the state is limited to presence only. The benefits and utility of ICT and Internet based tools for effective customer communication of Assam ass tourism destination is yet to be realised. Besides virtual tourism or pervasive environment architecture, etc are totally absent from the customer communication strategies of the state. Concerned authorities and DMOs in Assam should understand the tremendous potentials that virtual tourism holds, and try to add this to the existing customer communication strategies. Examples should be sought from other places like Mexico, Scotland, Las Vegas, etc which have reaped the sweet benefits of virtual tourism in the form of increased tourist inflows and much more popularity than Assam among potential tourists..

\section{REFERENCES}

[1] Gretzel, U. and D.R. Fesenmaier (2003) Searching for the future: white paper on technology and change in destination marketing, National Laboratory for Tourism \& Cho, Y., Wang, Y. \& Fesenmaier, D. R. (2003). Searching for Experiences - The Web- Based Virtual Tour in Tourism Marketing. Journal of Travel \& Tourism Marketing eCommerce, Philadelphia, PA

[2] Schroeder, Ralph (1996). Possible Worlds: The Social Dynamic of Virtual Reality Technology. Westview Press, Inc., Boulder, CO, USA.

[3] Boulos, M. N. K., Hetherington, L., \& Wheeler, S. (2007). Second Life: an overview of the potential of 3 -D virtual worlds in medical and health education. Health Information \& Libraries Journal, 24(4), 233245. doi: 10.1111/j.1471- 1842.2007.00733.x

[4] Novak, T. P. (2009). Quality of Virtual Life (QOVL). Draft of chapter to appear in "Transformative Consumer Research for Personal and Collective Well Being: Reviews and Frontiers, Mick, D., Pettigrew, S., Pechmann C., and Ozanne, J. Eds.

[5] Steventon, S., \& Wright, A. (2006). "Intelligent Spaces. The Application of Pervasive ICT". Berlin: Springer. 12(4), 1-17. 